\title{
A Study on Burden of Prehypertension in Youth (or Pediatric Hypertension) in West Bengal, India
}

\author{
Sourav RoyChoudhury ${ }^{1}$ Kaustav Nayek ${ }^{1}$ Jinia Saha ${ }^{1}$ 이 \\ ${ }^{1}$ Department of Pediatric Medicine, Burdwan Medical College and \\ Hospital, Burdwan, West Bengal, India \\ Address for correspondence Jinia Saha, MD, Department of Pediatric \\ Medicine, Burdwan Medical College and Hospital, Burdwan-713104, \\ West Bengal, India (e-mail: jiniasaha007@gmail.com).
}

J Child Sci 2021;11:e273-e279.

\begin{abstract}
Keywords

- obesity

- hypertension

- community

- pre-hypertension

- systolic hypertension

- children

Hypertension is a silent threat to the developing countries in recent times. The aim of this article was to determine the burden of prehypertension and hypertension among school-going children and the risk factors associated with those conditions. A crosssectional study was conducted among school-going children (6-18 years) in seven schools of Burdwan, West Bengal, India, selected by stratified random sampling from March 2017 to August 2018. Anthropometric and blood pressure measurements were obtained along with sociodemographic parameters. Prehypertension and hypertension were defined as per American Pediatric Society's definition. Mean age of the study population was $11.3 \pm 3.8$ years $(n=604)$. Prevalence of prehypertension and hypertension was estimated to be $5 \%$ and $4.6 \%$, respectively. Both prehypertension and hypertension were more common among children aged $>15$ years $(10.3 \%$ and 15.5\%). In logistic regression, the independent determinants of hypertension were higher socioeconomic condition, increasing age, obesity, increased intake of junk food, parental hypertension, and obesity among first-degree relatives. Proper preventive measures are the need of the hour to tackle the emerging epidemic at its root. Periodic measurements of blood pressure at regular intervals are advisable at community levels to recognize high-risk children, control obesity, and prevent irreversible end organ damages.
\end{abstract}

\section{Introduction}

Currently, India is going through a phase of epidemic transition, and noncommunicable diseases are on the rise compared with the communicable diseases. ${ }^{1}$ The World Health Organization (WHO) has reported prevalence of hypertension to decrease from $32 \%$ in 1980 to $27 \%$ in 2008 , but the prevalence is increasing in the developing countries including Southeast Asia and Africa. ${ }^{2}$ Many researchers thought that arterial hypertension has an early onset in early childhood. It has been estimated that $7 \%$ of adolescents with prehypertension are converted to hypertensive each year. ${ }^{3}$ Historically, hypertension in children, particularly in the younger age group, was thought to be rare and secondary

received

April 15, 2021

accepted after revision

August 19, 2021
DOI https://doi.org/

$10.1055 / \mathrm{s}-0041-1736240$.

ISSN 2474-5871. in origin. However, recent reports suggest an increased prevalence of childhood hypertension, particularly essential, also known as primary hypertension. No matter whether it is primary or secondary, it is always associated with significant end organ damage, which can be preventable by early diagnosis and treatment. However, a large portion of the disease still remains undiagnosed, known as the iceberg phenomenon. ${ }^{4}$ So far, there is no national program in India for this major problem. As the prevalence of obesity is less in developing countries as compared with industrialized Western countries, prevalence of hypertension is also different in developing countries. Among the few studies done in different parts of India, Mohan et al included 3326 school-going
(C) 2021. The Author(s).

This is an open access article published by Thieme under the terms of the Creative Commons Attribution License, permitting unrestricted use, distribution, and reproduction so long as the original work is properly cited. (https://creativecommons.org/licenses/by/4.0/)

Georg Thieme Verlag KG, Rüdigerstraße 14, 70469 Stuttgart, Germany 
children who were apparently healthy in northwest India. They found that incidence of hypertension was $6.6 \%$ and $2.2 \%$ among children of rural and urban areas, respectively. ${ }^{5}$ Gupta et al estimated the prevalence of hypertension as $6.6 \%$ among 3861 school-going children aged between 5 to 15 years in northern India. ${ }^{6}$ Sabapathy et al included school-children of Bangalore, south India, in their study and found that prevalence of prehypertension and hypertension was $2.7 \%$ and $3.2 \%$, respectively. ${ }^{7}$ Compared with this, overall prevalence of hypertension among adults in India was $11.4 \%$ (95\% confidence interval [CI], 11.4-11.5) as shown by Rauniyar et al. ${ }^{8}$ Our study aims to determine the prevalence of prehypertension and hypertension in the community levels of India in the eastern parts, which has not been documented on a large scale, and identify its contributing factors, which would establish an early prevention program in the long run.

\section{Materials and Methods}

A community based, observational, epidemiological, crosssectional study was conducted from March 2017 to August 2018 in seven different schools of Burdwan town, West Bengal, India after obtaining institutional ethical clearance (Memo No.BMC-2963/ Dated: 1/12/2016).

Total primary and secondary school-going children in Burdwan town are 19770 and 16632, respectively (source -District Office of Education). Taking 95\% CI and 4\% sampling error, total sample size was calculated to be approximately 591. A total of 604 students were selected by stratified random sampling. Children or parents who were not willing to participate in the study, suffered from any acute illness in the last 7 days, were suffering from any chronic or systemic disease, or were on any long-term medication were excluded from the study group. A detailed well-informed consent was taken from school authorities and parents. Mostly free periods and after school hours were utilized for conducting the study.

A semistructured pretested questionnaire was given to each parent regarding demographic details like age, sex, religion, residence, socioeconomic status, type of family, dietary habits, intake of junk food per week, and family history of hypertension and diabetes mellitus in both parents and first-degree relatives.

All anthropometric measurements like height and weight were taken for each child. Body mass index (BMI) was calculated in $\mathrm{kg} / \mathrm{m}^{2}$.

Blood pressure measurement procedure was explained in details to the children to alleviate any anxiety. They were given rest for 10 minutes before recording. It was recorded by mercury sphygmomanometer for three times in each visit, with at least a minimum gap of 5 minutes rest between each measurement.

\section{Definitions}

Classification of blood pressure ${ }^{9}$ :

- Normal: systolic blood pressure (SBP) and diastolic blood pressure (DBP) less than $<90$ th percentile.
- Prehypertension: SBP or DBP greater than or equal to 90th percentile but less than 95th percentile or BP levels greater than or equal to $120 / 80 \mathrm{~mm} \mathrm{Hg}$.

- Stage 1: SBP or DBP from 95th percentile to 99th plus $5 \mathrm{~mm}$ of $\mathrm{Hg}$.

- Stage 2: SBP or DBP greater than 99th percentile plus $5 \mathrm{~mm} \mathrm{Hg}$.

BMI: ${ }^{10}$ Age- and gender-specific BMI $\geq 95$ th percentile is defined as obese and $\mathrm{BMI} \geq 85$ th percentile but $<95$ th percentile is defined as overweight.

\section{Statistical Analysis}

Data collected was entered in Microsoft Excel datasheet. Categorical data were expressed in terms of proportion, whereas continuous data were expressed in terms of mean and standard deviation (SD). Data were represented in tables and figures. Chi-square test was used to check the significance of difference of proportions. Student's t-test and oneway ANOVA were used to check the significance of difference between two and more than two means. Significantly associated variables in contingency tables were further considered for correlation for calculating the degree and direction of association. Independent determinants of hypertension were identified for multivariate regression analysis after removal of confounding factors. All the statistical data analysis was performed by using SPSS software version 19.0. $p$-value $<0.05$ was taken as statistically significant.

\section{Results}

\section{Demographic Characteristics}

Different factors were considered and their association with study population determined, which has been summed up in -Table 1.

Out of 604 children included in the study, 257 (43\%) were females and 347 (57\%) were males. The age distribution of participants was as follows: $<9.9$ years, $34.4 \%$; 10 to 14.99 years, $44.0 \%$; $\geq 15$ years, $21.5 \%$. The religion distribution of participants showed: Hindus, 69.3\%; Muslims, 29.3\%; and others $1.3 \%$. As much as $75.3 \%$ of the population resided in cities, while $24.3 \%$ resided in villages.

\section{Prevalence of Hypertension}

The distribution of participants according to blood pressure measured was as follows: normotensives, 546 (90.4\%); prehypertensives, 30 (5\%); hypertensives, 28 (4.6\%).

\section{Analysis of Factors Responsible for Hypertension}

Association with type of food habits and obesity was analyzed, and the findings have been summed up in - Table 2 .

We observed both prehypertension and hypertension were more prevalent among $>15$ years age group $(10.3 \%$ and $15.5 \%$, respectively). A gradual and significant increase of both SBP and DBP was noted with increase in age. Both prehypertension and hypertension were more commonly observed among Hindus (5.5\% and 5.0\%, respectively). As much as $92.4 \%$ of children from Muslim and other 
Table 1 Distribution of the study population according to demographic parameters $(n=604)$

\begin{tabular}{|c|c|c|c|c|c|c|}
\hline Variables & $\begin{array}{l}\text { Normal } \\
\text { no. (\%) }\end{array}$ & $\begin{array}{l}\text { Prehypertension } \\
\text { no. (\%) }\end{array}$ & $\begin{array}{l}\text { Hypertension } \\
\text { no. (\%) }\end{array}$ & $\begin{array}{l}\text { SBP } \\
\text { Mean } \pm \text { SD }\end{array}$ & $\begin{array}{l}\text { DBP } \\
\text { Mean } \pm \text { SD }\end{array}$ & Statistical analysis \\
\hline \multicolumn{6}{|l|}{ Age (years) } & \multirow{5}{*}{$\begin{array}{l}x^{2}=65.3, p<0.05^{\text {a }} \text {, d.f. }=4 \\
\text { ANOVA F SBP }=83.3, p<0.05 \\
\text { a, d.f. }=3 \text { ANOVA F DBP }=75.5 \\
p<0.05^{\text {a }} \text {, d.f. }=3\end{array}$} \\
\hline$<6$ & $52(100.0)$ & $0(0.0)$ & $0(0.0)$ & $83.5 \pm 8.9$ & $55.2 \pm 4.6$ & \\
\hline $6-9.99$ & $153(98.1)$ & $2(1.3)$ & $1(0.6)$ & $87.3 \pm 9.2$ & $56.2 \pm 4.6$ & \\
\hline $10-14.99$ & $240(92.3)$ & $14(5.4)$ & $6(2.3)$ & $91.6 \pm 13.4$ & $61.2 \pm 7.3$ & \\
\hline$>15$ & $101(74.2)$ & $14(10.3)$ & $21(15.5)$ & $108.6 \pm 17.2$ & $67.4 \pm 8.9$ & \\
\hline \multicolumn{6}{|l|}{ Sex } & \multirow{3}{*}{$\begin{array}{l}x^{2}=0.2, p=0.9, \text { d.f. }=2 \\
\text { Student's } t S B P=0.0, p=1.0 \\
\text { Student's } t \mathrm{DBP}=0.8, p=0.29\end{array}$} \\
\hline Males & $315(90.7)$ & $17(4.9)$ & $15(4.4)$ & $93.6 \pm 14.7$ & $60.7 \pm 7.8$ & \\
\hline Females & $231(89.8)$ & $13(5.1)$ & $13(5.1)$ & $93.6 \pm 16.8$ & $60.9 \pm 18.6$ & \\
\hline \multicolumn{6}{|l|}{ Religion } & \multirow{3}{*}{$\begin{array}{l}x^{2}=1.3, p=0.5, \text { d.f. }=2 \\
\text { Student's } t \text { SBP }=0.9, p=0.4 \\
\text { Student's } \text { t DBP }=0.4, p=0.7\end{array}$} \\
\hline Hindu & $375(89.5)$ & $23(5.5)$ & $21(5.0)$ & $94.0 \pm 15.4$ & $60.7 \pm 8.0$ & \\
\hline Muslim + other & $171(92.4)$ & $7(3.8)$ & $7(3.8)$ & $92.8 \pm 16.2$ & $61.0 \pm 8.5$ & \\
\hline \multicolumn{6}{|c|}{ Socioeconomic status } & \multirow{4}{*}{$\begin{array}{l}x^{2}=65.3, p<0.05^{\text {a }} \text {, d.f. }=4 ; \\
\text { ANOVA F SBP }=83.3, p<0.05 \\
\text { a, d.f. }=3 \text {; ANOVA F DBP }=75.5 \\
p<0.05^{\text {a }} \text {, d.f. }=3\end{array}$} \\
\hline Upper & $95(88.0)$ & $6(5.6)$ & $7(6.4)$ & $84.2 \pm 11.4$ & $57.8 \pm 5.7$ & \\
\hline Middle & $402(90.5)$ & $23(5.2)$ & $19(4.3)$ & $94.3 \pm 15.6$ & $60.2 \pm 7.9$ & \\
\hline Lower & $49(94.2)$ & $1(1.9)$ & $2(3.9)$ & $95.5 \pm 16.0$ & $64.5 \pm 9.0$ & \\
\hline \multicolumn{6}{|l|}{ Place of residence } & \multirow{3}{*}{$\begin{array}{l}X^{2}=8.1, p=0.01, \text { d.f. }=2 ; \\
\text { Student's } t \text { SBP }=0.01 \\
p=0.99 ; \text { Student's } t \\
\text { DBP }=0.09, p=0.92\end{array}$} \\
\hline Urban & $420(92.3)$ & $19(4.2)$ & $16(3.5)$ & $93.5 \pm 14.4$ & $60.4 \pm 8.2$ & \\
\hline Rural & $126(84.6)$ & $11(7.4)$ & $12(8.0)$ & $93.8 \pm 18.8$ & $61.9 \pm 7.8$ & \\
\hline \multicolumn{6}{|l|}{ Type of family } & \multirow{3}{*}{$\begin{array}{l}x^{2}=2.6, p=0.27, \text { d.f. }=2 \\
\text { Student's } t S B P=0.39 \\
p=0.69 ; \text { Student's } t \\
\text { DBP }=0.27, p=0.78\end{array}$} \\
\hline Nuclear & $273(88.6)$ & $17(5.5)$ & $18(5.9)$ & $97.7 \pm 15.6$ & $62.3 \pm 8.9$ & \\
\hline Joint & $273(92.2)$ & $13(4.4)$ & $10(3.4)$ & $89.4 \pm 14.4$ & $59.2 \pm 7.0$ & \\
\hline
\end{tabular}

Abbreviations: DBP, diastolic blood pressure; d.f., degrees of freedom; SD, standard deviation; SBP, systolic blood pressure.

${ }^{a} p<0.05$ considered to be statistically significant.

Table 2 Distribution of the study population according to food habits and obesity in study population $(n=604)$

\begin{tabular}{|c|c|c|c|c|c|c|}
\hline Variables & Normal no. (\%) & $\begin{array}{l}\text { Prehypertension } \\
\text { no. (\%) }\end{array}$ & $\begin{array}{l}\text { Hypertension } \\
\text { no. (\%) }\end{array}$ & $\begin{array}{l}\text { SBP } \\
\text { Mean } \pm \text { SD }\end{array}$ & $\begin{array}{l}\text { DBP } \\
\text { Mean } \pm \text { SD }\end{array}$ & Statistical analysis \\
\hline \multicolumn{6}{|l|}{ Food habits } & \multirow{3}{*}{$\begin{array}{l}\mathrm{x}^{2}=2.3, p=0.30, \mathrm{~d} \\
\mathrm{f} .=2 ; \text { Student's } t \\
\mathrm{SBP}=0.70, p=0.48 \\
\text { Student's } t \mathrm{DBP}= \\
0.35, p=0.72\end{array}$} \\
\hline Vegetarian & $35(97.2)$ & $0(0.0)$ & $1(2.8)$ & $95.4 \pm 12.9$ & $61.3 \pm 7.4$ & \\
\hline Nonvegetarian & $511(90.0)$ & $30(5.3)$ & $27(4.7)$ & $93.5 \pm 15.8$ & $60.8 \pm 8.2$ & \\
\hline \multicolumn{6}{|l|}{ Junk food/week } & \multirow{3}{*}{$\begin{array}{l}\mathrm{x}^{2}=547.6, p<0.01 \\
\text { d.f. }=2 ; \text { Student's } t \\
\text { SBP }=18.97 \\
p<0.01 \text { a; Student's } \\
t \mathrm{DBP}=13.35 \\
p<0.01^{\text {a }}\end{array}$} \\
\hline$\leq 1$ & 544 (99.5) & $2(0.3)$ & $1(0.2)$ & $90.3 \pm 12.2$ & $59.9 \pm 7.2$ & \\
\hline$>1$ & $2(3.5)$ & $28(49.1)$ & $27(47.4)$ & $123.5 \pm 15.1$ & $73.2 \pm 6.7$ & \\
\hline \multicolumn{6}{|l|}{ BMI } & \multirow{4}{*}{$\begin{array}{l}\mathrm{X}^{2}=437.5, p<0.05 \\
\text { d.f. }=4 ; \text { ANOVA F } \\
\text { SBP }=355.2, \\
p<0.05, \text { d.f. }=4 ; \\
\text { ANOVA F DBP }=95.3, \\
p<0.05^{\text {a }} \text {, d.f. }=4\end{array}$} \\
\hline Normal & 489 (99.4) & $2(0.4)$ & $1(0.2)$ & $87.3 \pm 8.3$ & $55.1 \pm 5.9$ & \\
\hline Overweight & $50(89.2)$ & $3(5.4)$ & $3(5.4)$ & $91.3 \pm 11.8$ & $63.5 \pm 5.2$ & \\
\hline Obese & 7 (12.5) & $25(44.6)$ & $24(42.9)$ & $122.1 \pm 13.5$ & $72.3 \pm 6.2$ & \\
\hline
\end{tabular}

Abbreviations: BMI, body mass index; DBP, diastolic blood pressure; d.f., degrees of freedom; SD, standard deviation; SBP, systolic blood pressure. ${ }^{a} \mathrm{p}<0.05$ considered to be statistically significant. 
communities showed normal blood pressure level. There was no significant difference between the two groups. Both prehypertension and hypertension were more common among upper socioeconomic status (5.6\% and 6.4\%). Normotension was seen more commonly among lower socioeconomic status (94.2\%), which was statistically significant. Both mean SBP and DBP were gradually and significantly increasing with decrease in socioeconomic status. Both prehypertension and hypertension were more prevalent among rural population (7.4\% and $8.0 \%)$. Normotension was more common among urban children (92.3\%). This difference is significant statistically $(p<0.05)$. Mean SBP was higher among urban children, but the reverse was true for mean DBP: neither of these differences were statistically significant. Both prehypertension and hypertension were more prevalent among children of nuclear family (5.5\% and 5.9\%). Normotension was mostly found among children of joint families (92.2\%). This difference was not statistically significant.

Association with type of food habits and obesity was analyzed, and the findings have been summed up in - Table 2.
Prehypertension and hypertension both were more commonly seen among nonvegetarians (5.3\% and $4.7 \%$ ). While normotension was more prevalent among vegetarians (97.2\%), this difference was not statistically significant. Prehypertension and hypertension both were more commonly noticed among the children who consumed junk food $>1$ times in a week (49.1\% and $47.4 \%)$. Mean SBP and DBP were also higher among those who consumed junk-food $>1$ times in a week. Maximum prevalence of prehypertension and hypertension were noted among children with obesity (44.6\% and 42.9\%). A significant increase of both SBP and DBP were noted with increase in grades of obesity $(p<0.05)$.

Association of occurrence of hypertension in father, occurrence of hypertension in mother, presence of diabetes mellitus in father, presence of diabetes mellitus in mother, occurrence of hypertension in first-degree relatives, and occurrence of diabetes mellitus in first-degree relatives among study population were analyzed, and findings have been discussed in - Table 3.

Both prehypertension and hypertension were most commonly found among children of hypertensive fathers (46.0\% and $42.9 \%$ ). Mean SBP and DBP were also significantly higher

Table 3 Distribution of the study population according to risk factors in family in study population. $(n=604)$

\begin{tabular}{|c|c|c|c|c|c|c|}
\hline Variables & Normal no. (\%) & $\begin{array}{l}\text { Prehypertension } \\
\text { no. (\%) }\end{array}$ & $\begin{array}{l}\text { Hypertension } \\
\text { no. (\%) }\end{array}$ & $\begin{array}{l}\text { SBP } \\
\text { Mean } \pm \text { SD }\end{array}$ & $\begin{array}{l}\text { DBP } \\
\text { Mean } \pm \text { SD }\end{array}$ & Statistical analysis \\
\hline \multicolumn{6}{|c|}{ Hypertension in father } & \multirow{3}{*}{$\begin{array}{l}\mathrm{X}^{2}=509.4, p<0.01^{\mathrm{a}} \\
\text { d.f. }=2 ; \text { Student's } t \\
\text { SBP }=20.05 \\
p<0.01^{\mathrm{a}} ; \text { Student's } t \\
\mathrm{DBP}=13.52, p<0.01^{\mathrm{a}}\end{array}$} \\
\hline Absent & 539 (99.6) & $1(0.2)$ & $1(0.2)$ & $90.4 \pm 11.9$ & $59.5 \pm 7.1$ & \\
\hline Present & $7(11.1)$ & $29(46.0)$ & $27(42.9)$ & $121.7 \pm 17.0$ & $72.3 \pm 7.2$ & \\
\hline \multicolumn{6}{|c|}{ Hypertension in mother } & \multirow{3}{*}{$\begin{array}{l}\mathrm{X}^{2}=503.2, p<0.01^{\mathrm{a}} \\
\text { d.f. }=2 ; \text { Student's } t \\
\text { SBP }=18.3, p<0.01^{\mathrm{a}} \\
\text { Student's } t \\
\text { DBP }=13.24, p<0.01^{\mathrm{a}}\end{array}$} \\
\hline Absent & $537(99.8)$ & $0(0.0)$ & $1(0.2)$ & $90.4 \pm 11.8$ & $59.4 \pm 7.1$ & \\
\hline Present & $9(13.6)$ & $30(45.5)$ & $27(40.9)$ & $120.3 \pm 17.4$ & $71.8 \pm 7.8$ & \\
\hline \multicolumn{6}{|c|}{ Diabetes mellitus in father } & \multirow{3}{*}{$\begin{array}{l}\mathrm{X}^{2}=405.1, p<0.01^{\mathrm{a}} \\
\text { d.f. }=2 ; \text { Student's } t \\
\text { SBP }=15.9, p<0.01^{\mathrm{a}} \\
\text { Student's } t \\
\mathrm{DBP}=11.5, p<0.01^{\mathrm{a}}\end{array}$} \\
\hline Absent & $525(99.6)$ & $1(0.3)$ & $1(0.3)$ & $90.4 \pm 11.8$ & $59.4 \pm 7.0$ & \\
\hline Present & $21(27.3)$ & $29(37.7)$ & $27(35.0)$ & $115.8 \pm 19.9$ & $70.6 \pm 8.9$ & \\
\hline \multicolumn{6}{|c|}{ Diabetes mellitus in mother } & \multirow{3}{*}{$\begin{array}{l}\mathrm{X}^{2}=369.8, p<0.01^{\mathrm{a}} \\
\text { d.f. }=2 ; \text { Student's } t \\
\text { SBP }=13.6, p<0.01^{\mathrm{a}} \\
\text { Student's } t \\
\text { DBP }=10.8, p<0.01^{\mathrm{a}}\end{array}$} \\
\hline Absent & $526(98.8)$ & $4(0.8)$ & $2(0.4)$ & $90.8 \pm 12.1$ & $59.6 \pm 7.1$ & \\
\hline Present & $20(27.8)$ & $26(36.1)$ & $26(36.1)$ & $114.4 \pm 21.9$ & $114.4 \pm 21.9$ & \\
\hline \multicolumn{6}{|c|}{ Hypertension in relative in no. } & \multirow{4}{*}{$\begin{array}{l}\mathrm{X}^{2}=514.4, p<0.05^{\mathrm{a}}, \\
\text { d.f. }=4 ; \text { ANOVA F } \\
\text { SBP }=162.0, \\
p<0.05^{\mathrm{a}}, \text { d.f. }=4 ; \\
\text { ANOVA F DBP }=102.2, \\
p<0.05^{\mathrm{a}}, \text { d.f. }=4\end{array}$} \\
\hline 0 & $505(99.8)$ & $1(0.2)$ & $0(0.0)$ & $90.1 \pm 11.7$ & $59.2 \pm 6.8$ & \\
\hline $1-2$ & $41(75.9)$ & $11(20.4)$ & $2(3.7)$ & $101.5 \pm 17.6$ & $64.8 \pm 9.9$ & \\
\hline$\geq 3$ & $0(0.0)$ & $18(40.9)$ & $26(59.1)$ & $124.5 \pm 15.4$ & $74.3 \pm 5.7$ & \\
\hline \multicolumn{6}{|c|}{ Diabetes mellitus in relatives in no. } & \multirow{4}{*}{$\begin{array}{l}x^{2}=582.2, p<0.05^{a} \\
\text { d.f. }=4 ; \text { ANOVA F } \\
\text { SBP }=202.8 \\
p<0.05^{a}, \text { d.f. }=4 \\
\text { ANOVA F DBP }=95.3 \\
p<0.05^{a}, \text { d.f. }=4\end{array}$} \\
\hline 0 & $522(100.0)$ & $0(0.0)$ & $0(0.0)$ & $90.6 \pm 11.7$ & $59.5 \pm 7.1$ & \\
\hline $1-2$ & $23(95.8)$ & $1(4.2)$ & $0(0.0)$ & $87.3 \pm 13.1$ & $57.5 \pm 5.4$ & \\
\hline$\geq 3$ & $1(1.7)$ & $29(50.0)$ & $28(48.3)$ & $123.9 \pm 14.5$ & $72.6 \pm 6.1$ & \\
\hline
\end{tabular}

Abbreviations: DBP, diastolic blood pressure; d.f., degrees of freedom; SD, standard deviation; SBP, systolic blood pressure. ${ }^{a} p<0.05$ considered to be statistically significant. 
among children of hypertensive fathers than normotensive fathers. Both prehypertension and hypertension were most commonly found among children of hypertensive mothers (45.5\% and 40.9\%). Mean SBP and DBP were also significantly higher among children of hypertensive than normotensive mothers. Both prehypertension and hypertension were most commonly found among children of diabetic fathers (37.7\% and $35.0 \%$ ) and mothers (36.1\% both). Mean SBP and DBP were also significantly higher among children of diabetic fathers and mothers than nondiabetics.

Maximum prevalence of prehypertension and hypertension were noted among children with $\geq 3$ relatives with hypertension (40.9\% and 59.1\%). Maximum prevalence of prehypertension and hypertension were noted among children with $\geq 3$ relatives with DM (50.0\% and 48.3\%). A significant increase of both SBP and DBP were noted with increase in relatives with DM.

\section{Section 4: Multifactorial Analysis of SBP and DBP}

Ten of the independent variables, that is, age, socioeconomic status, fast-food consumption, presence of hypertension in father, presence of hypertension in mother, diabetes mellitus in father, diabetes mellitus in mother, presence of hypertension in relatives, and presence of diabetes mellitus in relatives had significant positive correlation with both the dependent variables, that is, SBP and DBP. Statistically significant correlation was also found between different independent variables, signifying that interaction between these variables may also influence the outcome variables (-Tables 4 and $\mathbf{5}$ ).

Logistic regression has showed the impact of unit change in independent variables on SBP. The significant predictors are age, BMI, junk food/week, hypertension in father, hypertension in mother, and obesity in relative. All these have a per se positive impact on SBP. As age increases by 1 year, SBP rises by $0.802 \mathrm{~mm}$ of $\mathrm{Hg}$. As BMI increases by 1 unit, SBP will rise by $1.171 \mathrm{~mm}$ of $\mathrm{Hg}$. Increase in junk food/week by
1 increases SBP by $8.034 \mathrm{~mm}$ of $\mathrm{Hg}$. If father had hypertension, then SBP was seen to increase by $7.435 \mathrm{~mm}$ of $\mathrm{Hg}$. If mother had hypertension, then SBP was seen to increase by $6.151 \mathrm{~mm}$ of $\mathrm{Hg}$. If first-degree relatives had obesity, then SBP was seen to increase by $3.311 \mathrm{~mm}$ of $\mathrm{Hg}$.

Logistic regression has showed the impact of unit change in independent variables on DBP. The significant predictors are socioeconomic status, age, BMI, and obesity in relative. All these have a per se positive impact on DBP. As socioeconomic condition improved by one unit, the DBP rose by $0.998 \mathrm{~mm}$ of $\mathrm{Hg}$. As age increased by one year, DBP rose by $0.467 \mathrm{~mm}$ of $\mathrm{Hg}$. As BMI increased by 1 unit, DBP was seen to rise by $0.801 \mathrm{~mm}$ of $\mathrm{Hg}$. If first-degree relatives had obesity, then DBP was seen to increase by $2.595 \mathrm{~mm}$ of $\mathrm{Hg}$.

\section{Discussion}

Chronic noncommunicable diseases are now becoming important public health problems in developing countries. There was a lack of significant research regarding prevalence of hypertension in children in India, especially in northeastern parts.

Out of the 604 study subjects, prevalence of prehypertension and hypertension was found to be $5 \%$ and $4.6 \%$. As much as $90.4 \%$ of study subjects were normotensive. Different authors estimated the prevalence of hypertension was different in different countries. Noubiap et al (Africa), Liang et al (China), Peters et al (United Kingdom), and Sinaiko et al found the prevalence of hypertension in the similar range in different countries of world. ${ }^{11-14}$ McNeece et al conducted their study among 7000 United States school children and found that prevalence of hypertension was $9.4 \%$. It may be due to higher socioeconomic status and greater prevalence of obesity among school-going children of United States. But they repeated blood pressure measurement for three times, and in the third measurement, they found that the prevalence was $3.4 \%$, which is similar to our findings. ${ }^{15}$ Hence,

Table 4 Showing multifactorial analysis of SBP

\begin{tabular}{|c|c|c|c|c|}
\hline \multirow[t]{2}{*}{ SBP } & \multirow[t]{2}{*}{ Coefficients } & \multirow[t]{2}{*}{$p$-Value } & \multicolumn{2}{|l|}{$95.0 \% \mathrm{Cl}$ for $\mathrm{B}$} \\
\hline & & & Lower bound & Upper bound \\
\hline (Constant) & 55.818 & $<0.001$ & 50.904 & 60.732 \\
\hline SES & 0.849 & 0.079 & -0.098 & 1.795 \\
\hline Age & 0.802 & $<0.001$ & 0.528 & 1.076 \\
\hline BMI & 1.171 & $<0.001$ & 0.888 & 1.455 \\
\hline Junk food/week & 8.034 & 0.041 & 0.328 & 15.741 \\
\hline Father hypertension & 7.435 & 0.019 & 1.245 & 13.625 \\
\hline Mother hypertension & 6.151 & 0.038 & 0.331 & 11.970 \\
\hline Father diabetes mellitus & 0.548 & 0.798 & -3.658 & 4.754 \\
\hline Mother diabetes mellitus & 0.292 & 0.885 & -3.662 & 4.245 \\
\hline Obesity in relative & 3.311 & 0.017 & 0.601 & 6.021 \\
\hline Diabetes mellitus in relative & 0.607 & 0.729 & -2.838 & 4.051 \\
\hline
\end{tabular}

Abbreviations: BMI, body mass index; $\mathrm{Cl}$, confidence interval; SBP, systolic blood pressure; SES, socioeconomic status. 
Table 5 Showing multifactorial analysis of DBP

\begin{tabular}{|l|l|l|l|l|}
\hline DBP & Coefficients & \multirow{2}{*}{-Value } & \multicolumn{2}{l|}{$\mathbf{9 5 . 0 \%}$ Cl for B } \\
\cline { 4 - 5 } & & & Lower bound & Upper bound \\
\hline (Constant) & 35.220 & $<0.001$ & 32.593 & 37.847 \\
\hline SES & 0.998 & $<0.001$ & 0.492 & 1.504 \\
\hline Age & 0.467 & $<0.001$ & 0.320 & 0.613 \\
\hline BMI & 0.801 & $<0.001$ & 0.649 & 0.953 \\
\hline Junk food/week & 0.975 & 0.642 & -3.145 & 5.095 \\
\hline Father hypertension & 2.901 & 0.086 & -0.408 & 6.211 \\
\hline Mother hypertension & 1.041 & 0.511 & -2.070 & 4.152 \\
\hline Father diabetes mellitus & 0.715 & 0.532 & -1.533 & 2.964 \\
\hline Mother diabetes mellitus & 0.527 & 0.625 & -1.587 & 2.640 \\
\hline Obesity in relative & 2.595 & $<0.001$ & 1.146 & 4.044 \\
\hline Diabetes mellitus in relative & 0.323 & 0.730 & -1.518 & 2.165 \\
\hline
\end{tabular}

Abbreviations: BMI, body mass index; $\mathrm{Cl}$, confidence interval; DBP, diastolic blood pressure; SES, socioeconomic status.

white-coat hypertension may also be responsible for higher prevalence of hypertension in the first time. Mohan et al found that the prevalence of hypertension was $6.6 \%$ and $2.2 \%$ among children of urban and rural areas, respectively. ${ }^{5}$ Laroia et al and Verma et al observed that prevalence of hypertension among children was $2.93 \%$ and $2.8 \%$, respectively. ${ }^{16,17}$ Verma et al repeated their measurement for a second time and found that prevalence of hypertension decreased to $1.1 \%$. Similarly, Gupta et al and Sabapathy et al also observed that prevalence of hypertension was $6.6 \%$ and $3.2 \%$, respectively.

We found that prevalence of both prehypertension and hypertension was higher among aged children. A significant increase of blood pressure was also noted with increase in age. Similar observation was also noted by Falkner et al, Rockwood et al, Wu et al, and Everett et al. ${ }^{18-21}$ Prehypertension and hypertension were more prevalent among female children, although not of statistical significance. Contrary to our findings, Everett et al and Reckeloff observed that prevalence of hypertension was significantly higher among males. ${ }^{22,23}$ Hypertension was more prevalent among children of Hindu religion, but this difference is not significant statistically. Similar observation was also made by Fitchet et $\mathrm{al}^{24}$ Prevalence of prehypertension and hypertension was higher among children of upper socioeconomic status. A gradual increase of mean blood pressure was also noted with increase in socioeconomic status. Similarly, Soylu et al noticed that children from lower socioeconomic status were less likely to develop hypertension. ${ }^{25}$ Contrary to our findings, Conen et al noticed an inverse association between hypertension and socioeconomic status. ${ }^{26}$ Prevalence of both prehypertension and hypertension was higher among rural children. No difference of mean blood pressure was noted between rural and urban children. Contrary to our finding, Daştan et al and SarrafZadegan et al observed that residing in an urban area is an independent risk factor of elevated blood pressure. ${ }^{27,28}$ Prevalence of both prehypertension and hypertension was more among children who take fewer vegetables and who consumed more junk food. Similarly, Sweazea et al also observed that vegetarian diet is helpful in reducing both SBP and DBP. ${ }^{29}$ Both prehypertension and hypertension were more common among children who have family history of hypertension and diabetes mellitus. Gando et al, Liu et al and Shen et al also observed a similar thing. ${ }^{30-32}$ Prevalence of both prehypertension and hypertension were more common among the obese. A gradual increase of blood pressure was noted with increase in BMI. Similar observations were also made by Gupta et al and Brouhard et al. 6,33

Independent variables, that is, increasing age, richer socioeconomic status, more junk food consumption, presence of hypertension in father, presence of hypertension in mother, and presence of obesity in relatives had significant positive correlation with both the dependent variables, that is, SBP and DBP in logistic regression analysis, which should be controlled at early stages to prevent early development of hypertensive states.

More research, preferably multicenter studies with adequate sample size need to be undertaken to find out the true prevalence of hypertension, as different studies estimated that prevalence of hypertension is different in different populations. Genetic studies were beyond our reach. Further studies should be undertaken to find out genetic cause of primary hypertension.

\section{Authors' Contributions}

S.R.C. conceived and designed the survey. J.S. drafted the manuscript. J.S. and S.R.C. were responsible for the collection of data. J.S. participated in statistical analysis of data and the interpretation of the data. K.N. critically evaluated the manuscript and rechecked all data. All authors reviewed and approved the final version of the manuscript for submission. 
Funding

None.

Conflict of Interest

None declared.

\section{References}

1 GBD 2013 Mortality and Causes of Death Collaborators. Global, regional, and national age-sex specific all-cause and cause-specific mortality for 240 causes of death, 1990-2013: a systematic analysis for the Global Burden of Disease Study 2013. Lancet 2015;385(9963):117-171

2 WHO. A Global Brief on Hypertension: Silent Killer, Global Public Health Crisis. World Health Day 2013 Geneva: World Health Organization Press; 2013

3 Falkner B, Gidding SS, Portman R, Rosner B. Blood pressure variability and classification of prehypertension and hypertension in adolescence. Pediatrics 2008;122(02):238-242

4 Vaidya A, Pokharel PK, Karki P, Nagesh S. Exploring the iceberg of hypertension: a community based study in an eastern Nepal town. Kathmandu Univ Med J (KUMJ) 2007;5(03):349-359(KUMJ)

5 Mohan B, Kumar N, Aslam N, et al. Prevalence of sustained hypertension and obesity in urban and rural school going children in Ludhiana. Indian Heart J 2004;56(04):310-314

6 Gupta AK, Ahmad AJ. Childhood obesity and hypertension. Indian Pediatr 1990;27(04):333-337

7 Sabapathy S, Nagaraju BA, Bhanuprakash CN. Prevalence of childhood hypertension and pre-hypertension in school going children of Bangalore rural district: a cross sectional study. Int J Contemp Pediatr 2017;4(05):1701-1704

8 Rauniyar SK, Rahman MM, Rahman MS, Abe SK, Nomura S, Shibuya K. Inequalities and risk factors analysis in prevalence and management of hypertension in India and Nepal: a national and subnational study. BMC Public Health 2020;20(01):1341

9 National High Blood Pressure Education Program Working Group on High Blood Pressure in Children and Adolescents. The fourth report on the diagnosis, evaluation, and treatment of high blood pressure in children and adolescents. National heart, lung, and blood institute Bethesda, MarylandNational institute of health, NIH publication 2005. Available at: https://pediatrics.aappublications.org/content/114/Supplement_2/555.long

10 Donohoue PA. Obesity. In: Behrman RE, Kleigman RM, Jenson HB, eds. Nelson Textbook of Pediatrics. 17th ed. Philadelphia: WB Saunders; 2004

11 Noubiap JJ, Essouma M, Bigna JJ, Jingi AM, Aminde LN, Nansseu JR. Prevalence of elevated blood pressure in children and adolescents in Africa: a systematic review and meta-analysis. Lancet Public Health 2017;2(08):e375-e386

12 Liang YJ, Xi B, Hu YH, et al. Trends in blood pressure and hypertension among Chinese children and adolescents: China Health and Nutrition Surveys 1991-2004. Blood Press 2011;20 (01):45-53

13 Peters H, Whincup PH, Cook DG, Law C, Li L. Trends in blood pressure in 9 to 11-year-old children in the United Kingdom 19802008: the impact of obesity. J Hypertens 2012;30(09):1708-1717

14 Sinaiko AR, Gomez-Marin O, Prineas RJ. Prevalence of "significant" hypertension in junior high school-aged children: the Children and Adolescent Blood Pressure Program. J Pediatr 1989;114(4 Pt 1):664-669

15 McNiece KL, Poffenbarger TS, Turner JL, Franco KD, Sorof JM, Portman RJ. Prevalence of hypertension and pre-hypertension among adolescents. J Pediatr 2007;150(06):640-644, 644.e1

16 Laroia D, Sharma M, Diwedi V, Belapurkar KM, Mathur PS. Profile of blood pressure in normal school children. Indian Pediatr 1989; 26(06):531-536

17 Verma M, Chhatwal J, George SM. Obesity and hypertension in children. Indian Pediatr 1994;31(09):1065-1069

18 Falkner B. Hypertension in children and adolescents: epidemiology and natural history. Pediatr Nephrol 2010;25(07):1219-1224

19 Rockwood MR, Howlett SE, Rockwood K. Orthostatic hypotension $(\mathrm{OH})$ and mortality in relation to age, blood pressure and frailty. Arch Gerontol Geriatr 2012;54(03):e255-e260

$20 \mathrm{Wu} \mathrm{S}$, Chen D, Zeng X, et al. Arterial stiffness is associated with target organ damage in subjects with pre-hypertension. Arch Med Sci 2018;14(06):1374-1380

21 Rockwood MR, Howlett SE. Blood pressure in relation to age and frailty. Can Geriatr J 2011;14(01):2-7

22 Everett B, Zajacova A. Gender differences in hypertension and hypertension awareness among young adults. Biodemogr Soc Biol 2015;61(01):1-17

23 Reckelhoff JF. Gender differences in the regulation of blood pressure. Hypertension 2001;37(05):1199-1208

24 Fitchett G, Powell LH. Daily spiritual experiences, systolic blood pressure, and hypertension among midlife women in SWAN. Ann Behav Med 2009;37(03):257-267

25 Soylu A, Kavukçu S, Türkmen M, Cabuk N, Duman M. Effect of socioeconomic status on the blood pressure in children living in a developing country. Pediatr Int 2000;42(01):37-42

26 Conen D, Glynn RJ, Ridker PM, Buring JE, Albert MA. Socioeconomic status, blood pressure progression, and incident hypertension in a prospective cohort of female health professionals. Eur Heart J 2009;30(11):1378-1384

27 Daştan İ, Erem A, Çetinkaya V. Urban and rural differences in hypertension risk factors in Turkey. Anatol J Cardiol 2017;18(01): 39-47

28 SarrafZadegan N, AminiNik S. Blood pressure pattern in urban and rural areas in Isfahan, Iran. J Hum Hypertens 1997;11(07): 425-428

29 Sweazea KL, Johnston CS, Miller B, Gumpricht E. Nitrate-rich fruit and vegetable supplement reduces blood pressure in normotensive healthy young males without significantly altering flowmediated vasodilation: a randomized, double-blinded, controlled trial. J Nutr Metab 2018;2018:1729653

30 Gando Y, Sawada SS, Kawakami R, et al. Combined association of cardiorespiratory fitness and family history of hypertension on the incidence of hypertension: a long-term cohort study of Japanese males. Hypertens Res 2018;41(12):1063-1069

31 Liu M, He Y, Jiang B, et al. Association between family history and hypertension among Chinese elderly. Medicine (Baltimore) 2015; 94(48):e2226

32 Shen Y, Chang C, Zhang J, Jiang Y, Ni B, Wang Y. Prevalence and risk factors associated with hypertension and prehypertension in a working population at high altitude in China: a cross-sectional study. Environ Health Prev Med 2017;22(01):19

33 Brouhard BH. Hypertension in children and adolescents. Cleve Clin J Med 1995;62(01):21-28 